\title{
"Para no poner en peligro la santa pobreza". Economía material en el Colegio de misiones de Chillán, 1756-1817
}

\section{"In order not to violate Holy Poverty". Material economy in the Chillán Mission College, 1756-1817}

\author{
Cristián LEAL PINO \\ Universidad del Bío-Bío, Chile \\ cleal@ubiobio.cl \\ David Rex Galindo \\ Universidad Adolfo Ibáñez, Chile \\ david.rex@uai.cl
}

Fecha de recepción: 06-04-2019

Fecha de aceptación: 29-06-2019

\section{RESUMEN}

Este artículo analiza la economía material del colegio franciscano de propaganda fide de San Ildefonso de Chillán durante la segunda mitad del siglo XVIII y los inicios del XIX, haciendo hincapié en las condiciones económicas desde una perspectiva monetaria como material, relacionado con el sustento corporal y espiritual del religioso y misionero. Nuestro objetivo es observar el concepto de pobreza que los frailes misioneros de Chillán practicaban en una época de cambios en materia económica en el Reino de Chile. Para ello hemos contado con una documentación existente en los archivos de Propaganda Fide de Roma, General de Indias, Histórico Nacional de España, Santiago de Compostela y Franciscano de Chile, la cual permitió conocer la realidad material del Colegio de Misiones de Chillán en el tránsito del siglo XVIII al XIX. Metodológicamente, contrastamos el ideal de pobreza establecido en su Regla y Estatutos, el cual conminaba a los frailes a vivir con rigurosidad dicho voto, y la realidad cotidiana de los religiosos expresada en sus cartas e informes. La documentación no sólo daba cuenta de sus positivas condiciones materiales de vida, sino que también de los cuestionamientos que los frailes seráficos hacían respecto a la pobreza, generando

\footnotetext{
* El artículo es resultado de los proyectos Fondecyt iniciación número 11160795, denominado: Vida conventual y formas de financiamiento en un Orden mendicante en Chile: Los franciscanos en el tránsito de la Colonia a la República, y del Proyecto Regular DIUBB número 191324 2/R titulado: Cultura material en la Orden franciscana: El Colegio de misiones de Chillán en tiempos de la Colonia y la República en Chile. Queremos agradecer a los evaluadores anónimos y a los editores de la Revista Vínculos de Historia por sus atinados comentarios para mejorar los argumentos y la base historiográfica de este ensayo. Cualquier error es desde luego responsabilidad única de los autores.
} 
en más de alguno cargo de conciencia. Las disputas por terrenos, dineros y bienes en general, existieron, olvidando lo dispuesto en su Regla y Estatutos.

Palabras clave: Cultura material, Pobreza, Colegio de misiones

Topónimos: Chillán, Reino de Chile

Periodo: 1756-1817

\section{ABSTRACT}

This article analyses the material economy of the Franciscan College of propaganda fide of San Ildefonso de Chillán during the second half of the 18th century and the beginning of the 19th century. It focuses on the economic conditions from monetary and material perspectives, in relation to the corporal and spiritual sustenance of friars and missionaries. Our objective is to study the concept of poverty practised by Chillán misssionaries during a time of economic changes in the Kingdom of Chile. We have consulted documentation from the repositories of the Propaganda Fide Archives in Rome, the General Archive of the Indies, the National Historical Archive in in Madrid, and the Franciscan archives in Santiago de Compostela and Santiago de Chile, which enabled us to unveil the material reality of the Chillán Mission College during the transitional period from the 18th to the 19th century. Methodologically speaking, we contrasted the ideal of poverty established in its Rules and Statutes, which rigorously guided the conduct of the friars, and the daily reality of their lives as illustrated by their letters and reports. This documentation reveals not only their prosperous material living conditions, but also their questioning of poverty, and the guilt that sometimes accompanied the latter. Disputes over land, money and property in general existed, aside from the provisions of its Rule and Statutes

Key words: Material culture, Poverty, Mission College

Place names: Chillán, Kingdom of Chile

Period: $1756-1817$

\section{INTRODUCCIÓN}

A mediados de 1758, escribía fray José Gondar, desde su Colegio de Propaganda Fide de San Ildefonso de Chillán, una misiva al guardián del colegio de Herbón en España en la que explicaba su llegada a Chillán y describía las condiciones tanto materiales como espirituales del colegio y las misiones fronterizas. La carta era una llamada de ayuda para el reclutamiento de más religiosos que desempeñaran el apostolado en Chile, donde, citando la célebre frase bíblica atribuida a Jeremías: parvuli petierunt panem, et non erat qui frangerit eis (Lamentaciones 4: Los niños piden pan, y no hay quien se lo reparta). No ocultaba Gondar el estado "malo y mal dispuesto" de la iglesia y convento, que tenía que hacerse "todo de nuebo". Sin embargo, para atraer a potenciales misioneros, advertía que el clima de la zona era similar al de España, con cuatro estaciones, aunque invertidas respecto al hemisferio norte. Además, la tierra, aunque "muy pobre en dinero", era "abundantísima de todo lo demás" para la colectación de limosnas de "pan, carne, vino, lanas, y todo lo demas necesario, para substentar a mas de cinquenta ... a mas de cien religiosos". De hecho, tal riqueza garantizaba la reconstrucción del colegio "para lo qual se quedan disponiendo los materiales necesarios". (Gondar, Cartas de los misioneros Colegio de Chillán, 1758: 168). Chillán prometía convertirse en un Edén en el que no faltaban los bienes materiales para saciar el cuerpo y las almas para alcanzar la gloria en la "santa empresa" de la evangelización.

Otras cartas de religiosos del colegio planteaban las mismas inquietudes sobre la falta de evangelizadores frente a las tareas pastorales entre católicos e indígenas no cristianos 
a la vez que describían la bonanza de la tierra y las posibilidades de limosnas que redundarían en bienes materiales para los misioneros. Por ejemplo, en 1768 fray Andrés Antonio Martínez reconocía al guardián del colegio de Herbón la necesidad de más misioneros "entre fieles e infieles", carestía todavía más acuciante tras la expulsión de los jesuitas el año anterior. Como aliciente, la tierra que esperaría a los potenciales misioneros era abundante: "las limosnas de trigo, carneros, bacas y bino son tan excesivas que, en concluyéndose la iglesia... ya será precisso que se minoren los limosneros, para no poner en peligro la santa pobreza". (Martínez, Cartas de los misioneros Colegio de Chillán, 1768: 175).

No deja de ser irónica esta preocupación, ya que los colegios de propaganda fide, fundados desde finales del siglo XVII y a lo largo de la siguiente centuria, eran un intento institucional franciscano para renovar el espíritu apostólico de la orden preservando al mismo tiempo el estricto cumplimiento de los votos de obediencia, castidad y pobreza. Sin embargo, las tensiones entre el ideal franciscano y la realidad cotidiana surgen una y otra vez en los escritos de los misioneros de estos colegios, tanto en sus cartas como en la documentación oficial e interna. En este artículo queremos exponer estas dificultades a través de la economía material de una comunidad religiosa como el colegio de misiones de Chillán, dedicado a la vida apostólica y espiritual que rechazaba estrictamente el lucro, la opulencia y la vanidad.

Nos interesa analizar una economía relacionada con el intercambio de bienes tangibles, de transacciones pecuniarias, de la permuta de recursos materiales, del abono de compensaciones para la consecución de un fin que pareciera contradecir el voto de pobreza que debieran observar los religiosos. Aunque reconocemos que la economía del colegio de Chillán estaba intrínsecamente relacionada con su labor espiritual dentro y fuera del colegio, y que algunas decisiones tomadas por las autoridades del colegio en cuestiones económicas parecieran encaminadas a lograr un bien social y caritativo, el uso pecuniario y de bienes tangibles suscitaba dudas, aunque fueran socialmente aceptadas. No se trata por lo tanto de analizar el componente moral ni espiritual de la economía del colegio como entidad independiente o dentro del tejido social de la región donde está situado sino de ver las contradicciones que implicaban las transacciones materiales con su propia definición de pobreza (Burns, 1991; Thompson, 1971).

Queremos demostrar que la vida de los frailes seráficos de Chillán se desarrollaba en condiciones muy superiores a la población que los circundaba, que llevó a los religiosos a un cuestionamiento interno sobre el significado de la pobreza y el modo de vida seguido puertas adentro. Es decir, utilizamos el estudio de la materialidad económica del colegio para cuestionar si se observó la pobreza que formaba parte de los votos de los frailes y estaba consignada en su Regla, Estatutos y Constituciones, analizando cómo se vivió en realidad, y cómo efectivamente se violentó en aras de posibilitar la evangelización o de un mejor bienestar para la comunidad de frailes. Las autoridades del Colegio de misiones de Chillán hacia fines del siglo XVIII e inicios del XIX, debieron enfrentar situaciones que en muchos casos les generó algún grado de conflicto de conciencia o al menos una reflexión en torno al ideal de pobreza. En varios documentos nos encontramos con alusiones a ello, ya sea el problema de las donaciones testamentarias, del uso del dinero, de cobros indebidos, arrendamiento de predios, aporte de dinero para la libertad de cautivos y cautivas, entre otros. En los ejemplos provenientes de las fuentes primarias observamos situaciones donde los frailes tuvieron que tomar decisiones en materia económica y no siempre apegados a sus normas.

Es de sobra conocido que el significado del voto de pobreza fue un motivo de intenso conflicto dentro de la orden franciscana desde sus comienzos a principios del siglo XIII hasta el punto que originó faccionalismos irreconciliables, cismas, persecuciones y ejecu- 
ciones de religiosos. Según el fundador Francisco de Bernardone, los frailes debían vagar y sobrevivir como vagabundos, mendigando en las ciudades y pueblos donde predicaban la palabra de su dios. La Regla de 1223 establece el espacio normativo para organizar, entre otras cosas, la vida espiritual y material de los religiosos en su quehacer diario. A pesar de que la Regla fue escrita como un mecanismo de gobierno para armonizar las voces más disonantes dentro de la comunidad franciscana, la posesión de propiedades se convirtió en una dificultad ineludible a medida que la orden se expandía al final del medioevo, generando cismas y escisiones alrededor de la interpretación de la pobreza a lo largo del periodo moderno, algunos de cuyos grupos serían partícipes de la evangelización americana (Le Goff, 2003; Vauchez, 2010).

Para el periodo colonial en América, la orden franciscana estuvo regida por los Estatutos Generales de la Orden Franciscana aprobados en 1621 en Segovia, en cuyo capítulo tercero sobre la guarda de la pobreza se establecían las directrices de cómo se debían administrar los recursos temporales de los religiosos franciscanos. Para evitar el contacto con bienes recibidos por donaciones de los feligreses, se instituía un administrador laico o síndico que controlaba los gastos e ingresos bajo la supervisión y consejo del ministro provincial o del guardián del convento (Estatutos Generales, 1622, 16-17). Posteriormente, las Constituciones de los colegios franciscanos de propaganda fide, emitidas en dos bulas papales en 1686, ordenaban a los religiosos y misioneros de los colegios a que únicamente mendigaran lo necesario para su sustento cotidiano, "sin que se atrevan á usar de comidas, y bebidas delicadas, ni elijan ir á las casas en que se les presenten cosas semejantes". Además, estas Constituciones exigían a los misioneros que siguieran el ejemplo mendicante del fundador Francisco de Bernardone, quien "quando le convidaban á comer los Potentados, y ricos, llevaba pedazos de pan, que mendigando habia juntado, y como pobre verdaderamente humilde, no quería comer los manjares delicados, que le ponían en la mesa" (Inocencio XI, Bula Ecclesiae Catholicae, 1686: 47-48).

Sin embargo, como ya hemos indicado en otro lugar, los religiosos de Chillán, una población situada al sur del Reino de Chile, en la periferia del imperio español, contaron con importantes ingresos y superávits procedentes de diversos mecanismos de financiación. Por una parte, ingresaban de la Corona un sínodo anual para desarrollar su labor en tierra de católicos e indios independientes no cristianos, el cual por lo general llegaba a destiempo, generando así una gran dependencia de otros recursos disponibles que debían suplir dichos inconvenientes. Además, demostramos que no fueron pocos los beneficios obtenidos de las propiedades y haciendas, los servicios religiosos como misas, entierros, y capellanías, las actividades prestatarias, las ventas de diversos productos y tierras, donaciones, así como las onerosas limosnas de los vecinos. Gran parte de lo ingresado era en plata y otra en especies, para concluir que se mantuvo un nivel elevado en lo material y económico (Leal, 2018).

En este artículo, nuestro objetivo es analizar cómo el Colegio de San Ildefonso de Chillán, que buscó renovar la misión apostólica de la orden franciscana en las remotas regiones del sur del Reino de Chile, enfrentó las necesidades materiales, ya fuera lícita como ilícitamente, manteniendo a la vez un discurso oficial de austeridad extrema. En la práctica, ante las necesidades crecientes de su labor evangelizadora y civilizadora, no siempre se cumplió con lo establecido en su Regla, en los Estatutos ni en las Constituciones en materia económica. Este artículo por lo tanto sigue las pistas dejadas por los autores de las cartas de los religiosos de Chillán con el objetivo de ahondar en los aspectos económicos que sustentaban el Colegio, tanto lo admitido por las normatividades canónicas como las actividades lucrativas que rozaban con lo inapropiado, e indaga las tensiones y conflictos internos sobre el significado de la pobreza. Nuestra pregunta de partida fue ¿Cómo se compaginó 
la existencia de bienes materiales y del apostolado con el voto de pobreza en el Colegio de propaganda fide de Chillán?

\section{UNA HISTORIOGRAFÍA ECONÓMICA DE LAS ÓRDENES RELIGIOSAS Y LA POBREZA}

Los estudios sobre las órdenes religiosas en América han girado fundamentalmente sobre su labor evangelizadora en medio de tierras de católicos y no cristianos, sus relaciones con el clero secular y los agentes civiles y administrativos coloniales, los elementos organizativos y los conflictos internos, y de mediadores políticos y al servicio del poder de la Corona Española. Con la excepción de los trabajos sobre los jesuitas y los conventos femeninos, la mayoría de las investigaciones sobre las órdenes religiosas en las Indias han dejado de lado los ámbitos de la cultura material que rodeaban la vida de los religiosos, de los recursos económicos con que vivían y de las redes económicas que tejieron con sus misiones y con las poblaciones coloniales. Hay importantes estudios que se han centrado en la relevancia de los conventos de monjas como instituciones crediticias durante el periodo colonial americano. Además, pensar en un análisis económico de las órdenes religiosas masculinas pareciera ser que es sólo propiedad de los jesuitas, como si las demás congregaciones religiosas no hubiesen tenido que administrar su patrimonio para poder vivir y llevar a cabo su labor espiritual (Burns, 1991; Cushner, 1983, 1984; Lavrin, 1998; Mörner, 1985; Sánchez, 2011).

Las excepciones son una base historiográfica para este artículo —aportes que iluminan la reflexión en torno a la cultura material a partir de estudios sobre otras órdenes religiosas masculinas y femeninas en el mundo hispánico moderno. Por ejemplo, Nieva Ocampo estudia las contradicciones que surgen en los conventos dominicos castellanos durante las reformas de la orden de finales del siglo XV y principios del XVI entre una normativa que exige una observancia del voto de pobreza y un aumento pragmático del uso y posesión de los bienes consecuencia de las necesidades materiales aupadas por un ambiente cada vez más intelectual; la mendicidad se convertía en vía de escape ante esta paradoja, a la vez que los prelados apoyaban la labor asistencial en los conventos dominicos castellanos durante las reformas (Nieva Ocampo, 2009). Al igual que para los dominicos, los debates sobre la pobreza fueron centrales en las reformas dentro de la orden franciscana desde sus inicios, rodeada de conflictos, cismas y escisiones, en una búsqueda de asimilación de modelos teológicos difíciles de cumplir en la cotidianeidad. Nuestro objetivo es estudiar estas paradojas al caso de estudio del colegio franciscano de propaganda fide de Chillán.

La historiografía argentina ha sido más proclive a estudiar el componente económico que sustentaba a la Iglesia, tanto regular como secular. Contamos también con significativos estudios sobre la limosna, la inversión, la pobreza individual, los bienes en común, y el crédito en contextos tardocoloniales, sobre todo la orden de los Betlemitas en el virreinato de la Plata (Mayo, 1991; Mayo, Peire, 1991), junto con el impacto de las fluctuaciones de la economía regional o local en las condiciones de vida en el convento de monjas dominicas de Santa Catalina en el Tucumán del siglo XVII y la transcendencia del crédito como mecanismo de subsistencia de esta comunidad de religiosas (Nieva Ocampo, 2008). Valentina Ayrolo por otra parte ha analizado el sustento del clero diocesano y las implicaciones de la reforma de aranceles sobre servicios cotidianos de su labor apostólica en la Córdoba tucumana de finales del siglo XVIII y principios del XIX (Ayrolo, 2001). Todos estos trabajos permiten visualizar lo transcendental que es adentrarse en la cultura material de una organización religiosa, en este caso de un colegio de misiones, para aproximarse a la historia económica de las zonas periféricas del imperio español. 
Si la historiografía de las órdenes religiosas mendicantes masculinas en América todavía está dando sus primeros pasos en materia económica, quienes han trabajado los colegios de propaganda fide franciscanos han descartado el ámbito económico de estas comunidades. Los dos estudios generales de los colegios y su apostolado no tratan su participación en las economías espiritual ni material, aunque algo sabemos de la vida cotidiana en su interior y algo más sobre la economía de las misiones de frontera (Saiz Díez, 1992; Rex Galindo, 2018; Archibald, 1978). Por ejemplo, algunos investigadores han puesto el énfasis en lo educacional (Pereira, 2002, 2005; Poblete, 2009), los procesos de evangelización (Rex Galindo, 2014a, 2014b), los conflictos en la frontera (Harrison, 2014), el rol político de los frailes, ya sea como mediadores en la frontera araucana para el caso chileno (Viñuela, 2015; Vega Arévalo, 2018) o en tiempos de la Independencia de Chile (Valenzuela, 2005; Cavieres, 2012); otros, han focalizado sus investigaciones en el rol evangelizador y civilizador (Leal, Quitral, 2017; Lagos, 1908) que cumplieron los misioneros en tierras pehuenches y mapuches durante el siglo XVIII (Leal, Quitral, 2017), ignorando decididamente el aspecto económico.

Partiendo de estos estudios y de fuentes primarias, en consecuencia, asumimos nuestra investigación desde una perspectiva económica, con el objeto de determinar las condiciones materiales en que vivían los frailes del Colegio de Propaganda Fide de San Ildefonso de Chillán hacia fines de la Colonia e inicios de la República, con la idea de observar las tensiones que generaron las disimilitudes entre el concepto de pobreza que los frailes manejaban y su aplicación.

\section{UN COLEGIO DE PROPAGANDA FIDE EN CHILLÁN: RAZONES ECONÓMICAS}

Desde finales del siglo XVII, los colegios de propaganda fide dieron un nuevo ímpetu al trabajo misionero de la orden franciscana. Fundados para renovar el apostolado y el modo de vida religioso, desde la fundación del primer colegio en la ciudad de Querétaro en la Nueva España, hasta las independencias americanas, se erigieron 29 colegios: 12 en España, 7 en la Nueva España y 10 en América del Sur. El Colegio de Propaganda Fide de San Ildefonso de Chillán, creado en 1756, fue un elemento más del engranaje evangelizador franciscano del siglo XVIII. Dichas fundaciones requerían aprobaciones locales, eclesiásticas, reales y papales, por lo tanto, eran procesos largos y costosos que implicaban a un gran número de actores, tanto locales como virreinales y en la corte madrileña. El caso de Chillán no fue diferente al de otros colegios (Saiz Díez; 1992; Rex Galindo, 2018).

Pese a su aislamiento, la pujante realidad económica de Chillán y sus alrededores en el siglo XVIII, posibilitó un adecuado desenvolviendo económico del Colegio. La demanda peruana de productos agropecuarios generó en la región una reorganización de la estructura agraria productiva, que en los siglos anteriores había estado dedicada a la ganadería. La llamada "fiebre del trigo", tuvo también repercusiones en las haciendas locales al punto de generar más de alguna alteración en el mercado interno regional (Casanova, 1994; Leal, 2018). Lo anterior, junto al arraigo de una comunidad de religiosos, con presencia desde finales del siglo XVI, confluyeron en la positiva realidad económica del colegio.

De la fertilidad de la tierra se harían eco las cartas que los misioneros mandaron a los guardianes del colegio de Herbón en España con que empezó este artículo. Además, las conexiones del colegio con las élites locales permitieron un flujo continuo de limosnas, que, junto a los sínodos reales y otros medios de atracción de capitales, hicieron que contara con recursos económicos importantes que le permitieron enfrentar los últimos años de la colonia de manera satisfactoria.de la vida en el colegio (Leal, 2018). Desde las mismas cartas emerge un discurso de optimismo en los inicios del colegio, donde las dificultades en las reparaciones de la iglesia y convento se yuxtaponen a la abundancia de la tierra. 
Figura 1. Colegios de misiones en Sudamérica hacia fines de la colonia

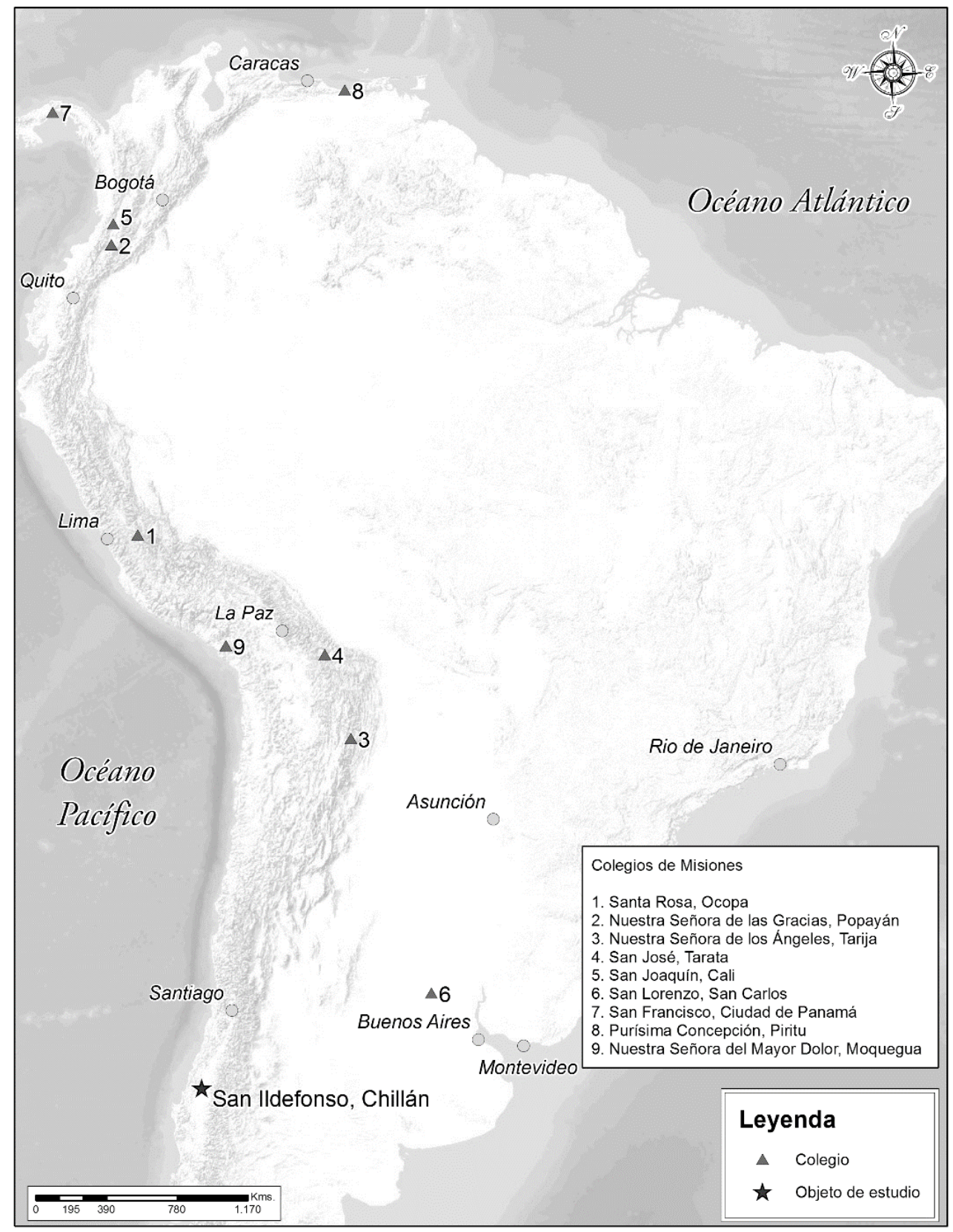

Fuente: elaboración propia a partir del libro de David Rex Galindo To Sin No More: Franciscans and Conversion in the Hispanic World, 1683-1830. Stanford University Press, Stanford, California y The Academy of American Franciscan History, Oceanside, California, 2018.

Sin embargo, sabemos que los inicios del Colegio en Chillán fueron complejos y difíciles, no sólo por las dificultades, sino también por los desastres naturales que afectaban la zona, como el terremoto ocurrido el año 1751 que tuvo nefastas repercusiones para el complejo conventual de Chillán. En un informe presentado al presidente Ambrosio Benavides en 1789, fray Miguel de Ascasubi describía aquellos primeros años diciendo: "No tenía el convento más vivienda que para cuatro o cinco religiosos", con muchas incomodidades. La iglesia, por su parte "se reducía a una capilla corta, estrecha y muy mal alhajada... (donde) faltaba casi de un todo" (Ascasubi, Informe cronológico de las misiones del Reino de Chile, 1789: 7). Esta realidad, sin embargo, cambiaría sustantivamente en un par de décadas, ya que en 1789, año en que escribía el informe, Ascasubi expresaba que, gracias al esfuerzo 
de prelados y súbditos, la iglesia estaba completamente alhajada con "la decencia que permite nuestro Instituto y la pobreza del país", con viviendas, oficinas y piezas necesarias "para una comunidad regulada de sesenta religiosos, trabajando todo sin otros arbitrios que las limosnas comunes con que la piedad de estos fieles nos socorre" (Ascasubi, Informe cronológico de las misiones del Reino de Chile, 1789: 7). Siguiendo el mismo lineamiento que las cartas de sus correligionarios al Colegio de Herbón, agregaba que el terreno era "el más ventajoso que puede desearse", tanto para la subsistencia de los religiosos, como por favorable y abundante "de toda suerte de carnes, granos, frutas y hortalizas..., como también y más principalmente para los varios ramos y ejercicios del ministerio apostólico" (Ascasubi, Informe cronológico de las misiones del Reino de Chile, 1789: 8).

Para 1790, 78 religiosos pertenecían al Colegio de Chillán, de los que 3 trabajan en el Seminario de Naturales para hijos de caciques que se había trasladado desde Santiago a las dependencias de los frailes seráficos de Chillán en el año de 1786, 25 evangelizaban en las misiones y 50 moraban en el colegio. Estos últimos debían entre otras cosas, atender a la población hispano-criolla aledaña a la ciudad de Chillán, hacia quienes desplegaban toda una labor pastoral además de ejercitarse en el ejercicio de las misiones populares entre los católicos en zonas más alejadas. La acción misionera era central en su proyecto evangelizador y civilizador, para lo que fundaron el hospicio de Santa Bárbara en el año 1758 desde el que adentrarse en tierras Pehuenches. Además, las misiones atendidas por los padres del colegio hacia el año de 1790 eran: Arauco, Tucapel, Valdivia, Mariquina, Arique, Niebla, Ganuehue, Quinchilca, Río Bueno, Cudico, Dalipulli. (Leal, Quitral, 2014).

También el Colegio de misiones de Chillán contaba con propiedades de singular importancia. Al momento de producirse el secuestro de bienes, el año 1824, en tiempos del gobierno de Ramón Freire, el inventario sólo registró las propiedades, dejando de lado el tema de los bienes semovientes y árboles frutales del instituto de Chillán. Entre las propiedades tenemos el fundo Los Guindos y los predios de El Castillo y La Esperanza, todas ellas ubicadas al oriente de la ciudad y que contribuían a la vida material de los religiosos del colegio (Iturriaga, 1995; Leal, 2013, 2014). El fundo Los Guindos, 672 cuadras, localizado a pocos kilómetros de la ciudad de Chillán, era el más importante, no sólo por su ubicación, sino que también por la producción en alimentos que genera para los frailes (Leal, 2013). Los otros fundos, emplazados en el sector precordillerano, de poco valor en cuanto a su productividad, eran de gran importancia para proveer de leña y madera, tema no menor en la reparación y construcción de edificios tanto del colegio como de las misiones en tierras de Arauco y Valdivia. El predio La Esperanza, con 448 cuadras y El Castillo, con 1.000, que junto al de Los Guindos sumaban la no despreciable cantidad de 2.122 cuadras. Terrenos con extensiones prediales de menor tamaño si comparadas con otros fundos de la zona o con las haciendas que contaban los jesuitas antes de su extrañamiento (Villalobos, Rodríguez, 1997; Leal, 2018).

El área territorial bajo dominio de los frailes, para los efectos de las limosnas, estaba claramente demarcada: entre el río Maule por el norte y el río Itata por el sur, estándoles permitido también adentrarse en Yumbel. Los limosneros recorrían un vasto y rico territorio, donde recogían no sólo animales, también trigo, lentejas, garbanzos y vino, que era de gran ayuda a la comunidad de religiosos. Fue tal la cantidad de limosnas en especies que se colectaban, que se conmutaban por dinero u otros productos que escaseaban; situación que no sólo era una práctica del colegio de Chillán, sino también habitual en los conventos de la Provincia (Leal, 2016). 
Figura 2. Límites limosna. Colegio de misiones de Chillán, s. XVIII

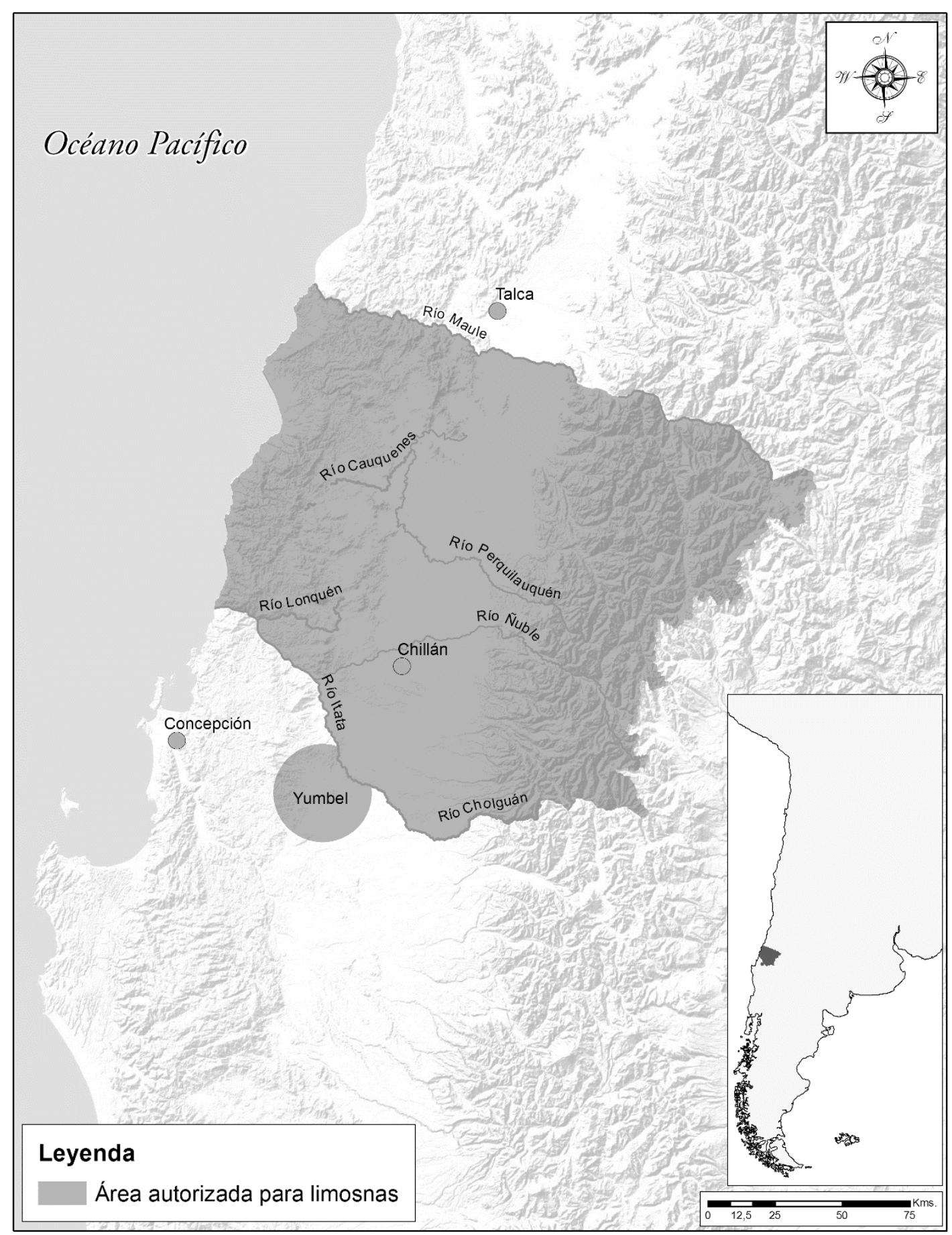

Fuente: Elaboración a partir de las Actas del Venerable Definitorio, Constitución de 1712, vol. 2 (1693-1713), Fondo Santísima Trinidad, Archivo Franciscano de Santiago de Chile, Rigoberto Iturriaga Carrasco.

Respecto a los ingresos, gastos y superávit/déficit (alcances), para el período 17641810, la situación era altamente positiva, registrándose déficit en sólo dos bienios en más de cuatro décadas. El siguiente cuadro da cuenta de ello. 
Tabla 1. Ingresos, gastos y superávit/déficit. Colegio de misiones de Chillán, 1764-1810

\begin{tabular}{|c|c|c|c|c|c|c|}
\hline \multirow[t]{2}{*}{ Período } & \multicolumn{2}{|c|}{ Entradas } & \multicolumn{2}{|c|}{ Gastos } & \multicolumn{2}{|c|}{$\begin{array}{l}\text { Superávit/ } \\
\text { Déficit }\end{array}$} \\
\hline & pesos & reales & pesos & reales & pesos & reales \\
\hline 1764-1765 & 2947 & 1 & 2358 & 2 & 588 & 7 \\
\hline $1765-1768$ & 4112 & 5 & 3123 & - & 988 & - \\
\hline 1768-1769 & 3118 & - & 1602 & 3 & 1.515 & 7 \\
\hline 1770 & 1978 & 2 & 975 & - & 1.003 & 2 \\
\hline 1771 & 2088 & 2 & 1057 & 5 & 1.030 & 5 \\
\hline 1771-1775 & 12109 & 4 & 10537 & 1 & 1.572 & 3 \\
\hline $1775-1776$ & 2395 & 3 & 2122 & 1 & 273 & 2 \\
\hline 1776-1777 & 1424 & 3 & 1058 & 3 & 366 & - \\
\hline 1779-1781 & 2130 & 5 & 1094 & 7 & 1.035 & 6 \\
\hline 1780-1781 & 2521 & 3 & 1126 & - & 1.395 & - \\
\hline 1779-1782 & 6520 & 7 & 4105 & - & 2.417 & 7 \\
\hline 1782-1783 & 2554 & - & 470 & 4 & 2.083 & 4 \\
\hline 1783-1784 & 3981 & 1 & 2529 & 4 & 1.451 & 5 \\
\hline 1795-1796 & 1089 & 6 & 1150 & 3 & -60 & 5 \\
\hline 1798-1801 & 7559 & 7 & 6285 & 7 & 1.273 & 7 \\
\hline $1799-1800$ & 2911 & 6 & 1375 & 5 & 1.536 & 5 \\
\hline 1801-1803 & 5030 & 3 & 3979 & - & 1.051 & 3 \\
\hline 1805-1807 & 10510 & 2 & 8463 & 4 & 2.046 & 2 \\
\hline 1807-1808 & 1432 & - & 1444 & - & -12 & - \\
\hline $1808-1810$ & 7659 & 7 & 6239 & - & 1.420 & 7 \\
\hline Total & 82.643 & 3 & 59.653 & 1 & 22.959 & 5 \\
\hline
\end{tabular}

Fuente: Leal 2018, Elaboración a partir de las Disposiciones Colegio Apostólico de Propaganda Fide de San Ildefonso de Chillán, 1764-1779 de Cristián Leal y Rigoberto Iturriaga, PAFSCh., Núm. 107, 2013 y de Disposiciones Colegio Apostólico de Propaganda Fide de San Ildefonso de Chillán, 1779-1810 de Cristián Leal y Rigoberto Iturriaga, PAFSCh, Núm. 109, 2014. 
Si bien existía el compromiso de un sínodo o asignación para el funcionamiento del Colegio, como ya indicamos, este llegaba por lo general tarde y por remesas, lo que hace difícil determinar su valor exacto. Lo cierto es que el síndico, que era un seglar, administraba estos recursos y los otros que entraban vía limosna. Así, con su función se evitaba que los frailes manipularan el dinero y por lo tanto quebrantaran el voto de pobreza. Estos síndicos del Colegio, no sólo existían en Chillán, también había uno en Santiago y otro en Concepción. Los síndicos compraban diversos "géneros" (alimentos, mercaderías, animales, etcétera) en las ciudades o en algún puerto utilizando parte del sínodo que la Corona le había otorgado (Leal, Iturriaga, Disposiciones del Colegio de Chillán, 2013-2014). En ocasiones administraban los sínodos de las misiones, como ocurrió con el Hospicio de Santa Bárbara y la misión de Tucapel, cuyos valores ascendían, al menos para el año 1782, a 500 y 660 pesos, respectivamente (Cuentas anuales, Colegio de Chillán, 1780-1811).

Los síndicos de Santiago y Concepción comunicaban los ingresos y gastos realizados en sus respectivos lugares, para que la comunidad de Chillán los tuviera en consideración al momento de hacer el balance económico. En Chillán destacó el síndico Santiago Roldán, en Santiago, Juan Gerónimo Ugarte y Pedro de Arrué y en Concepción Pablo Hurtado, quienes recibían el dinero de los oficiales reales. En las misiones también había mujeres que administraban los dineros, siendo una de ellas Clara Eslava, de la misión de Valdivia, que tenía propiedades en las inmediaciones de la capilla de dicha misión (Archivo Colegio Propaganda Fide Chillán, ACPFCh., Asuntos Varios 1791-1792, vol. 7).

El Colegio de Chillán tenía varias dependencias: iglesia, sacristía, refectorio, cocina, barbería, enfermería, panadería, carpintería y librería, lo que implicaba un gasto no menor en operarios y materiales para construir o reparar edificios. Como ya hemos dicho, el sínodo llegaba tarde y por remesas, por ello el colegio debió, como el resto de los conventos de la provincia, acudir a las limosnas y a las conmutaciones para asegura su dieta alimenticia, el vestuario y solventar diversos gastos de operación. De manera somera, el mayor porcentaje de ingreso lo aportaban los servicios religiosos que brindaba el colegio a la comunidad, principalmente misas, los entierros, honras, sermones y las capellanías, seguidos de remanentes de períodos anteriores, ventas y conmutaciones, y pagos por deudas de las misiones. Finalmente, el colegio contaba en menor medida con donaciones de particulares, réditos por préstamos y las limosnas, las cuales representan un porcentaje menor frente a los ítems anteriores. Lo que no recibían de su área de influencia, los religiosos lo acaparaban desde Concepción y Santiago, a donde viajaban a cuenta del sínodo o sus propios peculios para comprar víveres, vestimentas y ornamentos sagrados, tanto para el colegio como para las misiones (Leal, 2018).

\section{LOS LÍMITES DE LA POBREZA EN LA VIDA COTIDIANA DE LOS FRAILES MISIONEROS}

Junto a la realidad económica descrita en las páginas anteriores, los frailes también debieron hacer frente a situaciones no menos complejas emanadas de su cotidiano vivir y que ocuparon seriamente su atención. Su relación con la población hispano-criolla y los indígenas, posibilitaron su participación en acciones que fueron mucho más de allá de lo propiamente espiritual, debiendo lidiar con las disputas de tierras dejadas por los feligreses en testamentos, con el rescate de mujeres españolas cautivas, en controversias por bienes sagrados y profanos, por la asignación de dinero, entre otros. Las siguientes páginas dan cuenta de ello a través de cuatro casos particulares que ilustran las dificultades en encontrar un equilibrio entre la observancia del voto de pobreza y los quehaceres de los religiosos. 


\subsection{Los problemas asociados al disfrute de una donación testamentaria.}

Las capellanías y los censos eran las principales vías de ingreso en dinero que tenían los conventos. Estos ingresos no eran fruto de la mera casualidad, sino que eran consecuencia de las redes locales que habían tejido los religiosos en las comunidades donde se encontraba (Von Wobeser, 2010). Muchas veces, estas capellanías generaron conflictos entre las órdenes religiosas, especialmente cuando junto a un testamento aparecía un codicilo, que venía a manifestar la última voluntad de una persona.

El Colegio de Misiones de Chillán no estuvo exento de dichos conflictos. A raíz de una capellanía dejada al colegio por Joseph Beltrán en favor de su alma y de su mujer en un testamento en la década de 1750, dicha dación testamentaria fue objeto de consulta privada cuatro décadas después por las dudas que presentaba fray José Gondar sobre el uso que se hizo del dinero y el cargo de conciencia que le generaba. Este religioso, que estuvo directamente involucrado en las gestiones como guardián en la época de la donación, expresaba el problema que tenía en su "conciencia" y con su "alma de cabeza" y llena de "amarguras" para lo cual escribía a las autoridades de su colegio en 1791 tal vez acuciado por cargos de conciencia o como un examen de conciencia para con sus correligionarios (ACPFCh., Asuntos Varios 1791-1792, vol. 7, fj.109). El documento, que tiene un tono íntimo y revelador, nos da una oportunidad de ahondar en la problemática acerca del uso del dinero frente al voto de pobreza.

El testamento de Beltrán dejaba 2.000 cuadras a los frailes misioneros de Chillán en la isla del Maule, e incluía los certificados que daban facultades al Colegio para que nombrase patrón de dicha capellanía. José Gondar, en su consulta, y estimulado por su propia conciencia, planteaba si había sido lícita la venta de las dichas tierras por 1.000 pesos, los cuales se utilizaron para la fábrica del colegio en esos primeros años que presentaba estado de ruina. El colegio primero tuvo que sortear un codicilo que supuestamente favorecía a Pedro Norabuena como heredero de las tierras en disputa y por lo tanto generaba un problema no menor al guardián del Colegio y a su discretorio. Fray José Gondar planteaba que en su momento se invalidó el codicilo por no cumplir con las leyes castellanas sobre testamentos que requerían cinco testigos en el caso de no disponer de la rúbrica de un escribano. El codicilio sólo incluía las firmas de cuatro testigos (ACPFCh., Asuntos Varios 1791-1792, vol. 7, fj. 109).

Tras esta verificación legal, el discretorio, máximo órgano legislativo y ejecutivo del colegio, autorizó la venta y el síndico obtuvo la licencia del obispo de Concepción para llevar a cabo la operación, para luego establecer el número de 12 misas por año en memoria de Joseph Beltrán a cambio de los 1.000 pesos que "se [consumieron] en la fábrica de este sobredicho colegio". (ACPFCh., Asuntos Varios, 1791-1792, vol. 7, fjs. 109-112). Para ello, el religioso problematizaba alrededor de la licitud de la donación del terreno. Planteaba, primeramente: "Se me ha ofrecido la dificultad de que si la intención del testador ha sido (por no saber, como sabría la altísima pobreza que profesamos, no solo en particular, sino también en común) el que este colegio entrase a gozar y poseer dichas dos mil cuadras de tierras, y disfrutarlas como propias; en tal caso será el legado nulo o inválido" (ACPFCh., Asuntos Varios 1791-1792, vol. 7, fj.109v.).

Fray José Gondar indicaba que, si la intención del testador hubiese sido que después de sus días y los de su mujer, entrase el colegio a gozar y disfrutar dichas dos mil cuadras de tierra, sería su mandato inválido; y por consiguiente no las debían haber admitido, ni dispuesto de ellas, sino que debieron haber pasado a sus legítimos herederos o a los acreedores que tuviera el testador.

Continuaba fray José Godar con la problematización acerca del testamento de Beltrán con el caso comparable de su mujer María Mardones, quien dejó también dos mil cuadras a 
los padres mercedarios de Chillán, por mantener una capellanía que servían hace un largo tiempo y que estaban a la fecha "gozando dichas dos mil cuadras de tierras, y disponiendo de ellas como de suya propiedad". Veía el exguardián que no había mayor diferencia entre los dos testamentos y que parecería que por ello, la donación a los mercedarios sería inválida para ellos en esos términos, porque los religiosos del Colegio franciscano eran "incapaces de tener posesiones así en común como en particular", así estaba establecido en sus Estatutos y que por lo tanto la donación sería inválida.

No obstante, lo anterior, el exguardián de los misioneros franciscanos, recurría a Nicolás III, quien a través de la bula Exiit qui seminat, del año 1279, había pretendido solucionar las disputas sobre el alcance de la pobreza, estableciendo la observancia estricta de la misma. Había expresado en concreto que, si se dejaba algún bien a los frailes y no se explicitaba la forma de su tenencia, como era el caso del testamento de Joseph Beltrán, quedaban ingresados de "manera licita a los frailes", para no defraudar a quien lo había donado ni a los propios frailes que lo habían recibido (ACPFCh., Asuntos Varios 1791-1792, vol. 7, fj.109v.).

Finalmente, Gondar, mantenía que su yerro no estuvo en haber admitido y vendido las dos mil cuadras por medio del síndico, sino en que se hubiesen gastado y consumido los mil pesos, contradiciendo un decreto apostólico que entonces no se tuvo a mano y que se hace mención en la advertencia 19 del Manual del Escribano, en conformidad de lo dicho en un nuevo decreto hecho por la Sagrada Congregación de los Cardenales y con conocimiento del Papa Urbano Octavo, que "los bienes muebles o dineros que de aquí en adelante se adquieren para iglesias o conventos con carga de misas, sean puestos en los depositarios públicos o en persona fidedigna para que los dichos dineros o precios se conviertan en bienes raíces" (ACPFCh., Asuntos Varios 1791-1792, vol. 7, fj. 110). Igual situación debía ocurrir con los bienes inmuebles, es decir, ser enajenados por autoridad apostólica y con su dinero se vuelva a comprar otros bienes de las mismas características. Para concluir, Gondar hace una serie de sugerencias de cómo proceder, partiendo de la base de que la donación fue válida, aunque cuestionando la venta de los terrenos y el uso de los 1.000 pesos obtenidos. Es precisamente el uso de pecunia -contradictorio con el voto de pobreza de los religiosos y la prohibición del beneficio monetario- lo que más disputa el religioso; por ello, Gondar planteaba dos opciones al discretorio: la devolución de los 1.000 pesos al comprador de los terrenos o la obtención de una bula papal que diera por válido todo el proceso ya ejecutado con los dineros obtenidos tras la venta de los terrenos (ACPFCh., Asuntos Varios 1791-1792, vol. 7, fj. 111).

\subsection{La disputa de 150 pesos entre los colegios de Misiones y el de Naturales}

El mismo año de 1791 el gobierno del Reino de Chile solicitó al guardián del Colegio de misioneros fray Francisco Pérez la devolución de 150 pesos por el pago de manutención de un fraile que se desempeñaba como maestro de escuela desde 1789. El Colegio de Chillán en esa época era responsable del ya mencionado Seminario de Naturales para la educación de los hijos de los caciques y de una escuela pública adjunta al seminario, que era atendida por un fraile franciscano y financiada por la Real Hacienda. El aporte anual por el servicio del profesor de gramática de la escuela era de 150 pesos, salario cobrado por el Colegio de misiones, a raíz de que el fraile no pernoctaba en el Seminario de Naturales, sino con su comunidad del colegio. El guardián en carta al gobernador intendente Francisco de Mata Linares, con fecha Chillán 4 de enero de 1791, señalaba que el religioso que administraba la escuela pública, en calidad de maestro, debía vivir en el Seminario, pero que por razones diversas se había trasladado al Colegio de misioneros y por lo tanto abonando a dicha comunidad el dinero asignado a "cuenta del Erario Real para su manutención" (ACPFCh., Asuntos Varios, vol. 7, fj. 90). 
En dicha carta, el guardián del Colegio de misiones suplicaba a la autoridad civil se sirviera declarar si la escuela pública debía correr de cuenta de la Real Hacienda como accesoria al Seminario de Naturales, como había ocurrido hasta ahora. Concretamente si a la comunidad de frailes le correspondía alguna limosna para la subvención del maestro que hacía clases en ella y cuál sería ese monto. Luego, en otra carta, con fecha Chillán 1 de mayo de 1791, dirigida al Presidente de la Audiencia y Capitán General del Reino de Chile, la máxima autoridad civil en Chile, expresaba, a raíz de la respuesta que había tenido a su consulta anterior, que aceptaba y obedecía lo dispuesto y que ya "no exigirá esta comunidad en lo sucesivo de los fondos de la manutención del Religioso que la sirve en calidad de maestro" (ACPFCh., Asuntos Varios, vol. 7, fj. 91).

Por lo tanto, si bien el guardián entendía que debía reponer los 150 pesos que habían ingresado a la comunidad el año 1789, insistía en no haber percibido indebidamente el dinero, ya que el traslado del fraile al Colegio de misiones se había realizado con el consentimiento del padre Rector del Seminario de Naturales, siendo acogido sin objeciones como residente del Colegio. Al concluir su carta señalaba: "A vuestra señoría pido y suplico se sirva revocar en esta parte la citada Providencia, mandando que no se exija de esta Comunidad la cantidad expresada de 150 pesos" (ACPFCh., Asuntos Varios, vol. 7, fj. 91).

Sin embargo, el gobernador intendente Francisco de la Mata Linares, con fecha 6 de agosto de 1791, volvía a incidir en que el Colegio de misioneros debía reintegrar al Seminario de Naturales los 150 pesos. La respuesta del guardián, con fecha 13 de agosto, junto con señalar que acataría tal determinación, concluía diciendo que: "procuraré darle el correspondiente cumplimiento, luego que lo permitan las gravísimas urgencias, que actualmente padece esta Comunidad" (ACPFCh., Asuntos Varios, vol. 7, fj. 93).

\subsection{La disputa por bienes espirituales y profanos entre dos instituciones hermanas}

Entre los años 1788 y 1791 afloró un conflicto entre el Colegio de misiones de Chillán y el Colegio de misiones de San Carlos en San Lorenzo (actualmente San Lorenzo, Argentina), a raíz de unas alhajas, muebles, libros, ornamentos sagrados, alimentos y esclavos que Fray Juan Matud condujo desde Río Cuarto al Colegio de Chillán, al que había llegado al poco tiempo de su fundación en 1756. Matud había intentado infructuosamente fundar un colegio de propaganda fide en Río Cuarto en 1754, a donde supuestamente pertenecían los artículos y esclavos entes mencionados. Sus insistentes diligencias ante las autoridades del virreinato de la Plata finalmente posibilitaron que se aprobara el establecimiento de un colegio de propaganda fide en el convento de San Miguel del Carcarañal en 1784, una antigua estancia jesuita cedida para tal fin tras su expulsión en 1767, y que en 1786 sería trasladado a San Lorenzo (Caloni, 1884, 11; Pinillos, 1949; Mallo, 1998).

El franciscano Matud, luego de su experiencia como misionero en el Colegio de Chillán, en la región circundante al río Bío-Bío, fue nombrado comisario de misiones el año 1761, y durante los años de 1762 y 1763 recorrió España para colectar una misión de cincuenta misioneros que Ilegaría a Chillán en 1764. Entre 1778 y 1780, el padre Matud avanzó decididamente en la creación del Colegio de San Carlos en la antigua estancia jesuita de Carcarañal, del cual fue uno de sus fundadores (Mallo, 1998; Iturriaga, 2007).

El tema de los bienes que Ilegaron con Matud al Colegio de Chillán desde Río Cuarto, generó una larga disputa que trascendió el ámbito de lo local y llegó a oídos del Comisario General de Indias en Madrid, fray Manuel María Trujillo, quien reclamó que los bienes se devolvieran a San Carlos de San Lorenzo para así mantener la paz y tranquilidad que debía reinar entre los Colegios. No se querían litigios contrarios a la caridad y ajenos a la profesión, entendiendo que muchos de los bienes se habían consumido y otros deteriorados; 
el objetivo era que los colegios hicieran una composición amistosa y fraternal, digna del instituto franciscano.

En una misiva que escribió el guardián y discretorio del Colegio de San Carlos de San Lorenzo, fechadas el 5 de diciembre de 1788, a su contraparte del Colegio de Chillán hacían ver que a priori era necesario y prudente conocer el inventario de lo solicitado y que esto ya había sido aprobado por el Comisario General de Indias. Los misioneros de San Carlos pedían que les enviarán una lista de "todas la alhajas y muebles que estén en ser (su poder o propiedad), especialmente la Ara consagrada, los Cálices de Plata sobredorados, la Vinajeras y Platillos de Plata, las dos imágenes de Nuestra Señora con sus aderezos, y los esclavos" (ACPFCh., Asuntos Varios, vol. 7, fj. 72). La lista de los bienes contemplaba lo siguiente: junto al esclavo de más de 70 años, Miguel, casado con una esclava de persona seglar de Chillán se encuentra en el listado una imagen de la virgen de los Dolores, vestida y con ojos de cristal, un cáliz sobre dorado con patena y cucharita, una Ara y un misal con 30 años de servicio, una capa de tela de Damasco blanco, 6 candeleros de alquimia medianos, un ladrillo grande de alquimia para el servicio de la enfermería al momento de los baños de pies, 2 lienzos para hacer misión. A ello debemos agregar una serie de libros sobre mística fundamental, desengaños místicos, sermones, ejercicios de San Ignacio, cuaresmo del trinitario, manuales para los sacerdotes, moral, conceptos predicables, gritos del infierno, combate espiritual, entre otros.

La insistencia en el reclamo se fundamentaba por encontrarse el Colegio de San Carlos en un estado de indigencia. Dos años después, en otra carta el nuevo guardián del Colegio de San Carlos, Miguel Ruiz, con fecha 5 de diciembre de 1790, agradecía que el Colegio de Chillán hubiese cedido las alhajas y muebles, ofreciendo que se estableciera entre ambas comunidades la Hermandad quantum ad sufragia. Esta Hermandad, en términos concretos, significaba que, al fallecer un religioso de un colegio, el otro debía aplicar tantas misas como frailes existían en la comunidad, realizar una vigilia, misas cantadas con responso, y que los hermanos legos rezaran el "Pater Noster y Ave María cien veces".

Por su parte, el Colegio de Chillán, a través del secretario del discretorio, fray José Ruíz de Tagle, en carta del 21 de mayo de 1790, explicaba que por haber pasado tantos años y las sublevaciones de los indios, los bienes se habían deteriorado e incluso muchos de ellos fueron a dar al Hospicio de Santa Bárbara e incluso algunas fueron utilizadas en las misiones en tierras Pehuenches (ACPFCh., Asuntos Varios, vol. 7, fj. 74v.). Igualmente indica el guardián que algunos bienes se habían perdido, pero que de "Ios Negros conducidos por el expresado padre definidor había quedado solo uno", lo cual había sido comunicado oportunamente para que dispusieran de él.

La búsqueda de los bienes del Colegio de San Carlos se hizo todo lo meticulosamente posible dadas las circunstancias, según el guardián de Chillán, tanto en su colegio como en el Hospicio de Santa Bárbara. El que los objetos pasaran a las misiones, les parecía normal, toda vez que, para la fundación de las mismas, "no dio el Rey los utensilios necesarios, ni el Colegio tenía modo de proveerlos por su mucha pobreza". Las que quedaron en el Colegio "se consumieron y enajenaron... sin la mayor contradicción". Finalmente, los bienes identificados fueron devueltos: patenas, candelabros, cálices, lienzos, capas, entre otros. El único esclavo existente, llamado Miguel, no fue posible de ser devuelto, ya que a la fecha contaba con setenta años y estaba casado con una negra esclava de propiedad de un seglar de la ciudad de Chillán. Además, ambos colegios establecieron la Hermandad.

\subsection{Los frailes franciscanos en el rescate de cautivas y sus implicancias económicas.}

En el rescate de cautivas a manos de los grupos indígenas independientes en las zonas de frontera no sólo participaban los oficiales del ejército, caciques indígenas, funcionarios 
del poder real, hacendados, comerciantes reconocidos, sino que también los frailes franciscanos. Esta participación en el rescate de cautivas sitúa a los religiosos en el ámbito político, de las relaciones fronterizas, donde cumplieron un rol fundamental, demostrando el reconocimiento que tenían en la población aborigen. Esta faceta de mediación muestra las redes que tenían los misioneros con la población hispano-criolla, la administración y los indígenas. No era fácil lograr el objetivo de liberar a las cautivas, eran muchos los elementos que entraban en juego en las relaciones diplomáticas entre las autoridades hispanas y las naciones indígenas. Hay que destacar que la práctica de la cautividad de mujeres tenía como fin castigar principalmente "la capacidad moral y psicológica de resistencia de los enemigos, pues cada acto de arrebato cuestionaba la capacidad de protección de los más desprotegidos de una comunidad" (González, 2016, 190). De hecho, los líderes indígenas de estas naciones solicitaban la presencia de los frailes seráficos en los parlamentos. En pocos años habían generado las confianzas necesarias, para servir de mediadores ante situaciones complejas, como lo era el rescate de cautivas. Por su parte, las autoridades civiles del Reino de Chile comprendían que el rol del fraile era vital al momento de lograr las liberaciones. Para los religiosos, al igual que para las autoridades hispanas, el cautiverio femenino acentuaba la barbarie del mundo indígena, que violentaba el honor de la sociedad hispano-criolla tomando supuestamente, a través del cautiverio, la pureza y por ello la dignidad de las mujeres hispanas (González, 2016).

Hasta el momento, los estudios sobre estos rescates han estado centrados fundamentalmente en el rol que jugaron los religiosos y la red que configuraron a través del tiempo, pero no en el costo económico de los rescates, ni mucho menos en cómo se involucraron las instituciones religiosas en esta operación. La idea era también contribuir a la salvación de las almas, mediante el bautismo de las cautivas y de los hijos/as de las mismas que habían nacido de la relación con un indígena. En un informe del fraile Miguel Selles, con fecha 8 de julio de 1762, señala los distintos logros, siendo la educación de uno de los hijos de esta unión, quien enseñaba la doctrina cristiana en cualquier parte (Selles, Informe sobre el bautizo de cautivas, ACPFCh., Asuntos Varios, 1756-1763, vol. 1, imagen 019531 y ss.). La participación de los religiosos podía también avalar que un no deseado proceso de "indianización" por el que hubiera pasado la cautiva, particularmente "su sometimiento, así como la colonización de su cuerpo y de su vientre con la semilla de una estirpe mestiza" —-sobre todo en casos de cautiverios extensos, era atenuado con este discurso de fidelidad cristiana de las cautivas blancas liberadas (González, 2016, 206). Los frailes franciscanos en este rescate también comprometieron parte de sus recursos económicos, que llegaban tanto por el sínodo como de las limosnas, con la finalidad de lograr el objetivo, aunque a veces estos recursos se desviaron a las mejoras materiales del colegio, incurriendo en un uso ilegítimo de las donaciones.

En su artículo "Frailes y cautivas. Un caso de negociación interétnica en la frontera hispano-mapuche, 1746-1760", Rodrigo Escribano se adentra en el caso de Jerónima Rodríguez, que había sido tomada cautiva hacia el año 1740 por los Pehuenches en una de las malocas, cuyo captor la había incorporado a "su séquito de esposas y la empleó en los obrajes textiles y en las labores agrícolas" (Escribano, 2014: 18) y cuyo caso es también nuestro objetivo de estudio. Más allá de la descripción de las acciones en que participaron los frailes seráficos junto a los caciques, hacendados y autoridades del Reino, Escribano deja en claro no sólo las redes que habían tejido los religiosos, sino que también describe el sistema de intermediación que existía en el mundo fronterizo y su capacidad para generar recursos económicos y acuerdos políticos (Escribano, 2014: 17).

El año 1760 el padre Francisco Sánchez — que había llegado a Chillán el 5 de abril de 1758 con patente de Vice Comisario de Misiones- informaba a la Real Audiencia que 
el cacique Praynam tenía como una de sus esposas a una mujer natural de Buenos Aires llamada Jerónima Rodríguez, iniciándose un proceso de negociación que involucrará a distintos actores del mundo indígena como hispano-criollo (Escribano, 2014). Sin embargo, y a pesar del tiempo transcurrido, el tema de la cautiva Jerónima Rodríguez y otras mujeres españolas, será tema de un informe de fray Joseph de Gondar escrito el 19 de diciembre de 1791. La particularidad de este informe radica en que entrega información sobre el desvío de recursos para los rescates hacia las misiones y el Hospicio de Santa Bárbara. Se trata por lo tanto de información fundamentalmente económica, donde deja en evidencia la participación de los franciscanos a través del Colegio de misiones de Chillán, como del Hospicio de Santa Bárbara, en los procesos de liberación de cautivas y el desvío de fondos.

Con el título "Sobre el costo de las cautivas que se han rescatado", Gondar informaba al guardián de su colegio fray Francisco Pérez de las gestiones y el número de cautivas liberadas gracias a su labor. Señalaba que el Gobernador y Capitán General del Reino de Chile había reconocido al religioso a cargo del Hospicio de Santa Bárbara el título de vice comisario de misiones y que le había asignado "cierta cantidad de plata para el rescate de cautivas" (ACPFCh., Asuntos Varios, vol. 7, fj. 116v.). Los frailes se sumaron a estas transacciones, incluso pusieron el dinero del sínodo del Hospicio de Santa Bárbara y de las misiones, como de las propias limosnas para el pago de las cautivas. El propio colegio aparece como deudor de dinero del Hospicio de Santa Bárbara, a raíz de que dicho colegio había desviado parte de los recursos del hospicio a los rescates.

Las propias autoridades civiles se sumaron a la causa de los franciscanos de Chillán aportando dinero a los rescates. Son frecuentes las contribuciones que registra el síndico del colegio Juan de Arechabala, anotando en su libro de cuentas un ramo o ítem de ingreso para la liberación de las cautivas, siendo uno de los aportes el del Maestre de Campo, quien había donado cuarenta y cuatro pesos y dos reales para la libertad de una cautiva.

El informe mencionaba el ejemplo de Jerónima Rodríguez, que fue rescatada en el paraje de "Lunquimay", logrado después de "varios trabajos, contiendas y aumentos de pagas, que todas reguladas... al precio corriente... y el preciso vestido para dicha cautiva, importaron ciento cuarenta y tres pesos, no sumados lo que primeramente habían pedido la cantidad de ochenta pesos" (ACPFCh., Asuntos Varios, vol. 7, fj.117v.). También se pagaba la libertad de las cautivas en vestimenta, bienes tangibles, animales, entre los que encontramos: chupas, estriberas de alquimia, espuelas de hierro y alquimia, cascabeles, sombreros de vicuña, añil, animales mayores y menores. El propio sínodo que la Corona había asignado al colegio fue utilizado para el pago de los rescates, incluso las limosnas del sustento de las misiones fueron ocupadas para el mismo fin (González, 2015, 96 n14).

El informe de Gondar reparaba también en un rescate donde se liberaba una madre y su hija de "pecho". El importe de la madre fue una chupa colorada franqueada, un par de espuelas de alquimia que se consiguieron de la piedad cristiana de los habitantes de Chillán y un par de baratijas. El pago por la hija recién nacida, fueron un par de espuelas de plata, un poco de trigo, seis vacas y unos cortos donecillos. Según el testimonio de fray Esteban Rosales, que en aquellos tiempos vivía en el Hospicio de Santa Bárbara, se pagó por la hija cuarenta y cuatro pesos.

Un cuarto caso de rescate de cautivas tuvo como costo doscientos pesos "en cuya cuenta entran 25 vacas que el mismo [fray Joseph de Gondar] fue a entregar al indio que vendió la cautiva". Las vacas aportaron 100 pesos, tasadas a 4 pesos cada una. Sobre quien aportó los doscientos pesos no se logró establecer si había sido el Hospicio de Santa Bárbara o producto de las limosnas. De los cuatro rescates que hace mención el informe de Gondar, el valor pagado por la primera fue de 223 pesos, el de la hija de una cautiva 44 pesos dos reales (no aparece el valor de su madre), y la última de 200 pesos, sumando la 
cantidad de 467 pesos 2 reales. El informe igual reparaba en los costos que ocasionó el trabajo de los propios religiosos que participaron del rescate hasta entregar las personas cautivas a sus dueños, como también la manutención y salarios de los peones que las han recogido y conducido a lugares seguros.

\section{CONCLUSIONES}

Los cuatro estudios de caso descritos nos evidencian que los frailes, más allá de su vida propiamente espiritual, debieron hacerse parte de una serie de situaciones que tenían directa relación con lo material, donde el dinero era un tema no menor. Acabamos de ver cómo el colegio cuestionó internamente reclamos de donaciones, que en muchos casos llevaron años de pleito, incluso con otras órdenes religiosas así como con seglares; planteó supuestas malversaciones de asignaciones de dinero por funciones educacionales de algún fraile de la comunidad y para el rescate de cautivas; también se lamentaron entredichos con otros colegios, como el de San Carlos por ornamentos sagrados y otros bienes con la intención de guardar dinero para situaciones de crisis política. Todas estas situaciones ocasionaron más de algún conflicto de conciencia entre quienes dirigían los destinos del Colegio de Chillán, toda vez que se pensaba en el voto de pobreza y lo que establecía la Regla y sus Estatutos.

Las fuentes confirman que la realidad material del Colegio de misiones de Chillán hacia fines de la Colonia en Chile permitió una existencia próspera de más de medio centenar de frailes. Las redes tejidas por los religiosos seráficos, no sólo a partir del año 1756 para el Colegio de Chillán, sino que se puede extender incluso a la fundación del convento en el año 1585, permitieron relacionarse con la población hispano-criolla e indígena y mantener un tipo de relación más allá del sustento espiritual. Sin duda que la bonanza de la economía externa al colegio, de la región, conectada en el siglo XVIII con otros territorios, contribuyó a dicha prosperidad, como detallaban los escritos mandados desde Chillán al colegio de Herbón en Galicia, España. Los misioneros de propaganda fide de Chillán además se convirtieron en verdaderos agentes de la Corona y asumieron un rol político, de mediadores en muchos casos, de conflictos que se suscitaban del diario vivir.

El tema económico y de su relación con lo material también fue parte de su mundo y estuvo presente en cada una de sus acciones. No podemos descartar por insignificante el simple intercambio epistolar entre los frailes por el reclamo de los 150 pesos percibidos por un religioso a raíz de los servicios prestados, como ocurrió en el caso del Colegio de Naturales, donde se "educaban" a los hijos de los caciques. O el episodio donde se solicitaba restituir ornamentos sagrados y profanos, además de un esclavo a un Colegio hermano, debiendo trascurrir un largo tiempo para llegar a un acuerdo. O el hacer frente a un codicilo que cambiaba la voluntad originaria de un testador a raíz de unas tierras donadas. O la participación de los frailes en el rescate de cautivas, aportando no sólo con su presencia y prestigio, sino que, también facilitando y desviando, en calidad de préstamo, dineros que habían ingresado vía sínodo o de la limosna en especies que se encontraba tanto en el Colegio de misiones como en el Hospicio de Santa Bárbara.

Todas estas participaciones de los frailes generaron en algún momento cuestionamientos, una especie de "cargo de conciencia", que los llevó al menos a intentar buscar una explicación a lo ocurrido, recurriendo a los escritos jurídicos de la época, a bulas papales, a lo ocurrido en situaciones similares con otras órdenes religiosas, sobre el voto de pobreza de los frailes. La positiva realidad económica, las redes creadas en el tiempo en la zona, llevaron en algunas situaciones, a quienes dirigían el Colegio de misiones de Chillán, a transgredir su Regla y Estatutos. Lo cierto es que fue difícil para los frailes vivir en esta realidad material, al extremo de llegar a cuestionarse la "santa pobreza", que desde los tiempos de su fundador algunos habían querido mantener. 


\section{FUENTES}

Actas del Venerable Definitorio, Constitución de 1712, vol. 2 (1693-1713), Fondo Santísima Trinidad, Archivo Franciscano de Santiago de Chile (AFSCh.).

Cartas de los Misioneros del Colegio de Chillán (Chile), Archivo de la Provincia de Santiago de Compostela, carpeta 141.3, "Cartas de América", 1757-1768.

Disposiciones Colegio Apostólico de Propaganda Fide de San Ildefonso de Chillán. Primera parte: 1764-1779, PAFSCh., Núm. 107, 2013. Cristián Leal, Rigoberto Iturriaga.

Disposiciones Colegio Apostólico de Propaganda Fide de San Ildefonso de Chillán. Segunda parte: 1779-1810, PAFSCh., Núm. 109, 2014. Cristián Leal, Rigoberto Iturriaga.

Documentos varios sobre situaciones económicas del Colegio de misiones de Chillán. En Archivo del Colegio de Propaganda Fide de San Ildefonso de Chillán (ACPFCh.), sección Asuntos Varios 1791-1792, volumen Núm. 7.

Estatutos Generales de Barcelona para la familia Cismontana, 1621, Imprenta de los Heredereos de Juan García Infanzón, Madrid, 1746.

Historia de las misiones del Colegio de Chillán, Ediciones Herederos Juan Gil, Barcelona, España, 1908. Roberto Lagos.

Informe cronológico de las misiones del Reino de Chile hasta 1789, en Publicaciones del Archivo Franciscano, Santiago, PAFSCh., Núm. 49, 1997. Miguel Ascasubi.

Informe sobre el bautizo de cautivas, ACPFCh., Asuntos Varios, 1756-1763, vol. 1, imagen 019531 y ss. Miguel Selles

Informe del Estado de las misiones del guardián José María Sepúlveda, 7 de octubre de 1844. Archivo Histórico de Propaganda Fide (AHPF), Roma, América Meridionale, vol. 7.

Inocencio XI, Bula Ecclesiae Catholicae, 1686, en Joaquín Ibarra (comp.), (1781): Breve apostólico de Pio Sexto, y Estatutos Generales para la erección y gobierno de las custodias de misioneros observantes de Propaganda Fide en las Provincias Internas de Nueva España, Madrid, D. Joachín Ibarra, Impresor de Cámara de S. M.

\section{BIBLIOGRAFÍA}

Archibald, R. (1978): The Economic Aspects of California Missions, Washington, DC, The Academy of American Franciscan History.

Ayrolo, V. (2001): "Congrua sustentación de los párrocos cordobeses. Aranceles eclesiásticos en la Córdoba del ochocientos", Cuadernos de Historia. Serie Economía y Sociedad, 4, pp. 39-66.

Burns, K. (1991): Colonial Habits: Convents and the Spiritual Economy of Cuzco, Peru, Durham, Duke University Press.

Caloni, V. (1884): Apuntes históricos sobre la fundación del Colegio de San Carlos y sus misiones en la provincia de Santa Fe, Buenos Aires, Imprenta y Librería de Mayo.

Casanova Guarda, H. (1994): Diablos, Brujos y Espíritus Maléficos. Chillán, un proceso judicial del siglo XVIII, Temuco, Ediciones Universidad de La Frontera.

Cavieres Figueroa, E. (2012): Sobre la Independencia en Chile. El fin del Antiguo Régimen y los orígenes de la representación moderna, Valparaíso, Ediciones Universitarias de Valparaíso.

Cushner, N. P. (1983): Farm and Factory: The Jesuits and the Development of Agrarian Capitalism in Colonial Quito, Albany, State University of New York Press.

Escribano Roca, R. (2015): "Frailes y cautivas. Un caso de negociación interétnica en la frontera hispano-mapuche, 1746-1760", en Cañedo y Argüelles Fábrega, T. (coord.), América. Cruce de miradas, vol. 2, Alcalá de Henares, Universidad de Alcalá, pp. 551575. 
González, Y. (2015): “A propósito de cautivos y mestizos al revés. Tráfico y circulación de cautivos en la Araucanía de los siglos XVIII y XIX", en González, Y. (ed.), Diálogos de Historia. Miradas y alcances de la investigación en Chile con enfoque regional, Temuco, Ediciones Universidad de La Frontera, pp. 71-95

- (2016): "Indias blancas tierra adentro. El cautiverio femenino en la Frontera de la Araucanía, siglos XVIII y XIX", Anuario Colombiano de Historia Social y de la Cultura, vol. 43, núm. 2, pp. 185-214.

Harrison, J. (2014): "Negociando la supervivencia en la frontera de Texas: grupos indígenas en a las misiones franciscanas", en Sanz Camañes, P. y Rex Galindo, D. (coords.), La frontera en el mundo hispánico, Quito, Abya-Yala, pp. 483-502.

Iturriaga Carrasco, R. (1995): Secuestro de Bienes, 1824, Publicaciones del Archivo Franciscano de Santiago, núm. 40.

- (2007): 4268 y otros datos... Elenco de religiosos de la Orden Franciscana que han pasado por Chile, Publicaciones del Archivo Franciscano de Santiago, núm. 100.

Lavrin, A. (1998): "Cofradías novohispanas: economías material y espiritual", en Martínez López-Cano, M. P., Von Wobeser, G., Muñoz Correa, J. G. (coords.), Cofradías, capellanías y obras pías en la América colonial", México, Serie Historia Novohispana, 61, Universidad Nacional Autónoma de México, pp. 49-64.

Le Goff, J. (2003): San Francisco de Asís, Madrid, Ediciones Akal, S.A.

Leal Pino, C. (2013): "La realidad económica del Colegio de Propaganda Fide de Chillán en el periodo tardo colonial", en Cáceres, J., Tobar, L. y Leal, C. (eds.), Lecturas y (RE) Lecturas en Historia Colonial II, Santiago, Andros impresores, 215-237.

- (2016): Utopía y realidad. Franciscanos en Chile, 1750-1850, Concepción, Ediciones Universidad del Bío-Bío.

- (2018): "Una micro-economía en la frontera sur del Reino de Chile: el Colegio de misiones de Chillán hacia fines de la Colonia", Santiago, Revista Intus-Legere, vol. 12, núm. 1, pp. 21-44.

Leal Pino, C. y Quitral, A. (2014): "El Colegio de Propaganda Fide de Chillán y el hospicio de Santa Bárbara en la evangelización de la frontera sur andina del Reino de Chile: 1758-1766", Anuario de Historia de la Iglesia en Chile, Santiago, Seminario Pontificio Mayor, vol. 32, 73-94.

- (2017): "Evangelización y occidentalización en la frontera sur del Reino de Chile. Los Franciscanos del Colegio de Misiones de Chillán, s. XVIII", Revista Historia y MEMORIA, Tunja, 15, pp. 139-168.

Mallo, B. A. (1998): "El itinerario pastoral del padre Juan Matud y la Fundación del Colegio Apostólico de San Carlos", Anuario de Historia de la Iglesia en Chile, Santiago, Seminario Pontificio Mayor, vol. 16, pp. 39-56.

Mayo, C. y Peire, J. (1991): "Iglesia y crédito colonial: La política crediticia de los conventos de Buenos Aires (1767-1810)", Revista de Historia de América, México, Instituto Panamericano de Geografía e Historia, 12, pp. 147-157.

Mayo, C. A. (1991): Los betlemitas en Buenos Aires: convento, economía y sociedad (17481822), Excma. Diputación Provincial de Sevilla.

Mörner, M. (1985): Actividades políticas y económicas de los jesuitas en el Río de la Plata, Buenos Aires, Hyspamerica.

Nieva Ocampo, G. (2008): "Crisis económica e identidad religiosa de un monasterio femenino en época de los Austrias: Santa Catalina de Córdoba del Tucumán (1613-1700)", Hispania sacra, 60 (122), pp. 423-443.

- (2009): “«Dejarlo todo por Dios, es comprar el cielo»: El voto de pobreza, la mendicidad y el asistencialismo entre los dominicos castellanos (1460- 1550)", Hispania sacra, 
61(124), pp. 483-512.

Pereira, K. (2005): "Del Colegio al Seminario de Naturales: Los franciscanos y la educación indígena en Chile, 1786-1811", en Millar, R. y Aránguiz, H. (eds), Los Franciscanos en Chile: Una historia de 450 años, Santiago, Academia Chilena de la Historia, pp- 171186.

- (2002): El Real Colegio de Naturales, Santiago, Publicaciones del Archivo Franciscano de Santiago de Chile, núm. 73.

Pinillos, T. (1949): Historia del Colegio de San Carlos de San Lorenzo, Buenos Aires.

Pinto Rodríguez, J. y Rodríguez Córdova, I. (2014): Expansión capitalista y economía mapuche: 1680-1930, Temuco, Ediciones Universidad de La Frontera.

Poblete, M. (2009): "Prácticas educativas misionales franciscanas, creación de escuelas en territorio mapuche y significado de la educación para los mapuches-huilliche del siglo XVIII y XIX", Revista Espacio Regional, Osorno, vol. 2, núm. 6, pp. 23-33.

Rex Galindo, D. (2014a): "La sacramentalización de la frontera. El programa misionero franciscano del Colegio Apostólico de Tarija en Bolivia al final de la colonia", en Sanz Camañes, P. y Rex Galindo, D. (coords.), La frontera en el Mundo Hispano, Quito, Abya-Yala, pp. 437-458.

- (2014b): "Primero hombres, luego cristianos: Un análisis sobre la conversión forzosa en la frontera de Texas", Colonial Latin American Historical Review CLAHR, vol. 2, núm. 3, pp. 405-432.

- (2018): To Sín No More. Franciscans and conversion in the Hispanic world, 1683-1830, Stanford, Stanford University Press; Oceanside, Academy of American Franciscan History.

Sáiz Díez, F. (1992): Los Colegios de Propaganda Fide en Hispanoamérica, Lima, CETA.

Sánchez, R. (2011): "La empresa económica jesuita en el obispado de Concepción: El caso de los colegios San Bartolomé de Chillán y Buena Esperanza", Revista UNIVERSUM, Talca, Universidad de Talca, núm. 26, vol. 2, pp. 215-243.

Thompson, E. P. (1971): "The Moral Economy of the English Crowd in the Eighteenth Century" Past \& Present, núm. 50, pp. 76-136.

Valenzuela, J. (2005): "Los Franciscanos de Chillán y la Independencia: Avatares de una comunidad monarquista" en Revista HISTORIA, núm. 38, vol. I, enero-junio, pp. 113158.

Vauchez, A. (2010): Francisco d'Assisi. Tra storia e memoria, Torino, Giulio Einaudi editore. Vega Arévalo, C. A. N. (2018): "«Parvuli petierunt panem ét non erat qui frangeret eis»: El Colegio de Propaganda Fide de Chillán en el acontecer Borbón, siglo XVIII", Tesis de Licenciatura, Santiago, Universidad de Chile.

Villalobos, S. y Rodríguez, C. (1997): “El espacio rural Longaví-Ñuble, 1737”, Cuadernos de Historia, Universidad de Chile, núm. 17, pp. 105-144.

Viñuela, R. (2015): "Los Franciscanos del Colegio de Propaganda FIDE de San Ildefonso de Chillán como mediadores políticos en la Frontera Araucana del siglo XVIII", en CañedoArgüelles Fábrega, T. (coord.), América Cruce de Miradas, España, 2 volúmenes, Universidad de Alcalá, pp. 577-602.

Von Wobeser, G. (2010): El Crédito Eclesiástico en la Nueva España, siglo XVIII, México, UNAM, Instituto de Investigaciones Históricas, Fondo de Cultura Económica. 